\title{
Streptococcus pneumoniae in the nasal cavity of mice causes lower respiratory tract infection after airway obstruction
}

\author{
Y. IIZAWA, N. KITAMOTO, K. HIROE and M. NAKAO \\ Pharmaceutical Research Laboratories III, Pharmaceutical Research Division, Takeda Chemical Industries Ltd, \\ 2-17-85 Jusohonmachi, Yodogawa-ku, Osaka 532, Japan
}

\begin{abstract}
A model of persistent colonisation in the nasal cavity of mice by Streptococcus pneumoniae has been established. $S$. pneumoniae NNP-4 was introduced to the lungs of CBA/J mice at a density of $c .10^{4} \mathrm{cfu} / \mathrm{lung}$ by an aerosol method and a high dose of ampicillin was administered $1 \mathrm{~h}$ after infection. This antibiotic eliminated bacteria from the lungs and trachea, but did not affect the bacterial counts in the nasal cavity. In mice given ampicillin, the bacteria were recovered from the nasal cavity only more than 2 weeks after infection, but IgG antibody against the colonising organisms was produced in sera around day 8 after infection. Airway obstruction was induced by intratracheal injection of formalin $2 \%$ into mice. Organisms appeared in the lungs in greater numbers when formalin was injected before the antibody production than when the immunity was established. In the early stages of infection, $10^{3}-10^{4} \mathrm{cfu}$ appeared in the lungs $6 \mathrm{~h}$ after the formalin injection and the bacterial counts increased to $c .10^{6} \mathrm{cfu}$ within $24 \mathrm{~h}$. When ampicillin was administered again $1 \mathrm{~h}$ after formalin was given, no bacteria were recovered from lungs $6 \mathrm{~h}$ later. However, in some of the mice given ampicillin after formalin, bacteria appeared in the lungs on the next day and the bacterial counts increased thereafter. These results suggest that $S$. pneumoniae in the nasal cavity invade the lower respiratory tract and that these organisms can localise and proliferate in lungs in the event of damage to the airway.
\end{abstract}

\section{Introduction}

Streptococcus pneumoniae is one of the major causes of bacterial pneumonia [1-4]. Pneumococci are frequently isolated from the nasopharynx of healthy people, especially young children [5-7], and pneumococcal pneumonia is believed to be the result of colonisation of the nasopharynx and spread of the bacteria to the lower respiratory tract $[6,8]$. However, as the mechanisms involved in the invasion of pneumococci from the nasopharynx to the lung are poorly understood [9-11], it is important to clarify these so that prophylactic and therapeutic measures for pneumococcal pneumonia may be developed.

Specific and non-specific defences protect the lower respiratory tract. Nasopharyngeal carriage may result in an immune response with production of IgG and secretory IgA antibodies capable of eliminating pneumococci $[6,12]$; also, the incidence of pneumococcal infections is highest in infants whose production of antibody in response to pneumococcal nasopharyngeal carriage is relatively weak $[12,13]$.

Received 6 Nov. 1995; accepted 9 Nov. 1995.
In addition, filtration, cough reflex, secretions and mucociliary transport are considered to be important non-specific mechanisms of protection in the respiratory tract [9] and the incidence of pneumococcal pneumonia is greatly increased in people with altered clearance mechanisms, such as cigarette smokers, and those who have chronic bronchitis, asthma, chronic obstructive pulmonary disease and viral respiratory infections $[8,14]$.

The purpose of this study was to examine the significance of altered clearance mechanisms whereby pneumococci that colonise the upper respiratory tract can infiltrate the lungs and cause pneumonia. A model of persistent colonisation with $S$. pneumoniae in the nasal cavity of the mouse was established and the effect of airway obstruction by intratracheal injection of formalin was examined.

\section{Materials and methods}

\section{Bacteria}

S. pneumoniae NNP-4 was kindly provided by K. Matsumoto, Institute of Tropical Medicine, Nagasaki 
University, Japan. Its serotype was 28 , as determined by the Quellung reaction with capsule type-specific antisera (Statens Seruminstitut, Copenhagen, Denmark).

\section{Mice}

Female CBA/J mice (Charles River Japan, Inc., Japan) 5-7 weeks old and weighing 16-21 $\mathrm{g}$ were used throughout the experiments. They were caged in groups of 10 and given food and water ad lib.

\section{Model of intranasal colonisation with $S$. pneumoniae}

S. pneumoniae NNP-4 was grown overnight at $37^{\circ} \mathrm{C}$ on Trypticase Soy Agar (TSA; BBL Microbiology Systems, Cockeysville, MD, USA) supplemented with bovine blood $10 \%$. Organisms from this culture were transferred to Trypticase Soy Broth (TSB, BBL); this was then centrifuged at $8000 \mathrm{~g}$ for $20 \mathrm{~min}$ at $20^{\circ} \mathrm{C}$. The cell pellet was washed with TSB and suspended in appropriate amounts of distilled water supplemented with TSB $0.1 \%$. Mice were placed in an exposure chamber and subjected to an aerosol of the bacterial suspension, contained in a nebuliser, at a pressure of $1.5 \mathrm{~kg} / \mathrm{cm}^{2}$ for $40 \mathrm{~min}$. To eliminate the bacteria from the middle and lower respiratory tract, ampicillin (Meiji Seika Kaisha Ltd, Tokyo, Japan) was administered subcutaneously $1 \mathrm{~h}$ after the aerosol challenge with $S$. pneumoniae NNP-4. The MIC of ampicillin to S. pneumoniae NNP-4 was $0.05 \mu \mathrm{g} / \mathrm{ml}$.

\section{Bacteriological examination}

Counts of bacteria in lungs, trachea and nasal washings were made as described previously [15]. Mice were anaesthetised with ether and bled from the axillary artery and vein. The lung and trachea were homogenised in $4 \mathrm{ml}$ and $2 \mathrm{ml}$ of sterile distilled water respectively. The nasal cavity was washed with $1 \mathrm{ml}$ of sterile distilled water and drained from the external nares. Serial dilutions of the homogenates and washings were plated on TSA supplemented with bovine blood. The plates were incubated overnight at $37^{\circ} \mathrm{C}$, and colonies were counted. Results are presented as the $\log$ number of $\mathrm{cfu} / \mathrm{ml}$ per organ or $\mathrm{cfu} / \mathrm{ml}$ of nasal washings. In addition, the distribution of bacteria to liver, spleen and kidneys was examined by pressing the central cut surfaces of the organs on to TSA supplemented with bovine blood, incubated overnight at $37^{\circ} \mathrm{C}$.

\section{Antibody determination}

The antigen for the microplate wells was prepared by heating S. pneumoniae NNP-4 suspended in phosphatebuffered saline (PBS: Dulbecco formula (modified) without magnesium and calcium; Flow Laboratories, Inc., McLean, VA, USA) at an approximate concentration of $10^{9} \mathrm{cfu} / \mathrm{ml}$ for $30 \mathrm{~min}$ at $100^{\circ} \mathrm{C}$. The heat-killed
S. pneumoniae NNP-4 cells were washed once with PBS and adsorbed on to the microwells by direct incubation overnight at $4^{\circ} \mathrm{C}$. Micro-ELISA was performed on test serum with a Microwell ELISAmate kit (Kirkegaard and Perry Laboratories, Gaitherburg, MD, USA) with alkaline phosphatase-conjugated affinitypurified goat anti-mouse IgG ( $\gamma$-chain specific; Kirkegaard and Perry Laboratories) as a second antibody. The enzyme substrate was $p$-nitrophenyl-phosphate, and the optical densities were read in a Microplate reader (Labsystems Multiskan Bichromatic, Finland) at $405 \mathrm{~nm}$.

\section{Airway obstruction}

Mice were anaesthetised with an i.p. injection of $50 \mathrm{mg}$ of sodium pentobarbital $/ \mathrm{kg}$ body weight. After exposure by small vertical midline cervical incisions, mice were intubated trans-orally with a blunt 22-gauge needle guided along the trachea to just within the intrathoracic cavity and $20 \mu \mathrm{l}$ of formalin $2 \%$ (Wako Pure Chemical Industries Ltd, Osaka, Japan) diluted with saline were injected. Skin incisions were closed with Alon Alpha A (Sankyo Co., Ltd, Tokyo, Japan).

\section{Results}

\section{Establishment of model for intranasal colonisation with S. pneumoniae NNP-4}

When $S$. pneumoniae NNP-4 localised in the lungs of $\mathrm{CBA} / \mathrm{J}$ mice at a density of c. $10^{4} \mathrm{cfu} / \mathrm{lung}$ by an aerosol method, the bacterial counts in the lungs and trachea of some mice were maintained at the initial level for 1 week after infection. However, there was considerable fluctuation in the numbers of bacteria in individual mice. On the other hand, bacterial counts in the nasal cavity increased from $10^{3}$ to $10^{4} \mathrm{cfu}$ in a day and remained relatively unchanged until 2 weeks after the aerosol challenge (data not shown).

To obtain a model of persistent colonisation in the nasal cavity only, the effect of ampicillin on the bacterial counts in the lungs, trachea and nasal cavity was first examined. Ampicillin was administered $1 \mathrm{~h}$ after the aerosol challenge and bacterial counts were done on the day after infection (Fig. 1). Counts decreased in proportion to the dose in lungs and trachea and ampicillin $200 \mathrm{mg} / \mathrm{kg}$ eradicated the bacteria from those organs. However, bacterial counts in the nasal cavity were not influenced even by a dose of ampicillin $200 \mathrm{mg} / \mathrm{kg}$. These results suggest that the model of persistent colonisation in the nasal cavity by $S$. pneumoniae NNP-4 could be established by the administration of ampicillin $200 \mathrm{mg} / \mathrm{kg} 1 \mathrm{~h}$ after the bacterial challenge. Differences in the bacterial counts in the respiratory tract of mice given $200 \mathrm{mg} / \mathrm{kg}$ of ampicillin $1 \mathrm{~h}$ after infection were examined next. Counts of $c .10^{4} \mathrm{cfu}$ were maintained in the nasal 


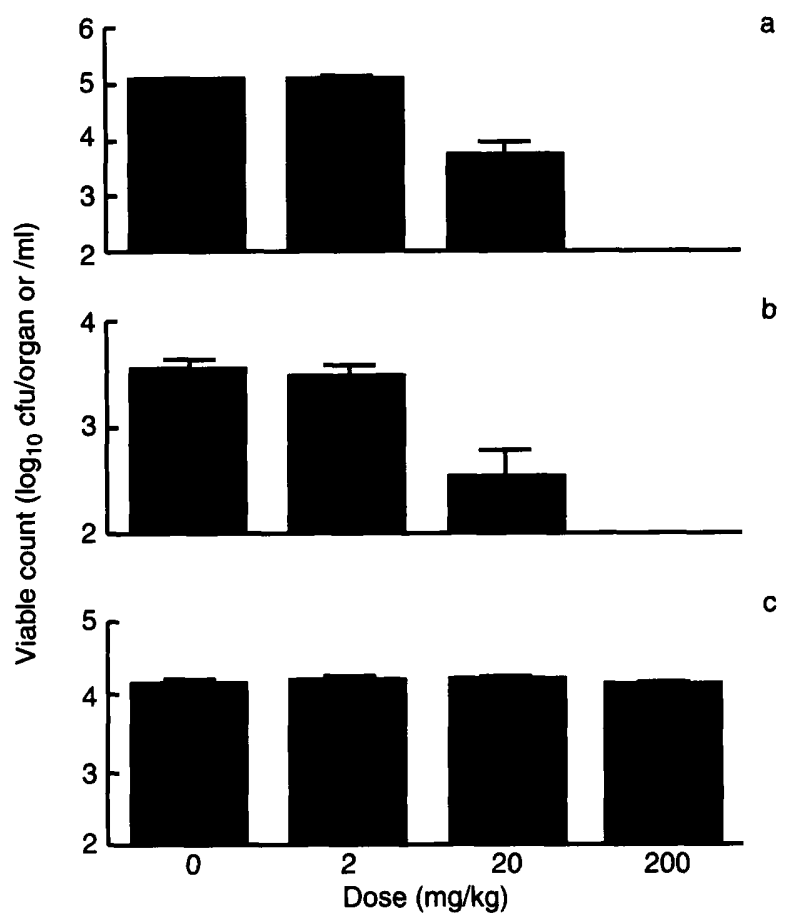

Fig. 1. Influence of treatment with ampicillin on bacterial counts in (a) lungs, (b) trachea and (c) nasal cavity of $\mathrm{CBA} / \mathrm{J}$ mice infected with $S$. pneumoniae NNP-4 by an aerosol method. Ampicillin was administered subcutaneously $1 \mathrm{~h}$ after the aerosol challenge. Bacterial counts were examined on the day after infection. Data are expressed as mean and SD of five mice.

cavity for up to 14 days after the aerosol challenge and counts in the nasal cavity gradually decreased thereafter (Fig. 2). On the other hand, bacteria were not isolated from the lungs for a period of 14 days after infection and only a small number from the trachea on days 5 and 7 after infection. Furthermore, no bacteria were recovered from the liver, spleen or kidneys throughout the observation period. Thus, the reason that $S$. pneumoniae NNP-4 existed in the nasal cavity alone for at least 2 weeks was presumed to be because of the ampicillin treatment.

\section{Production of antibody in serum against the} colonising organisms in nasal cavity

Nasopharyngeal colonisation by $S$. pneumoniae may result in an immune response and most infections occur during the first week of carriage, probably as the result of sensitisation and production of IgG that follow colonisation $[6,8,9]$. The kinetics of serum IgG antibody level against $S$. pneumoniae NNP-4 in mice with nasal cavity colonisation were examined. The serum antibody level of mice not treated with ampicillin, in which a certain number of bacteria were present in the lungs, was also examined. IgG antibody against the colonising organisms in the nasal cavity appeared around day 8 after infection, even in mice given ampicillin, although the antibody level was slightly lower than in mice not given ampicillin (Fig. 3).

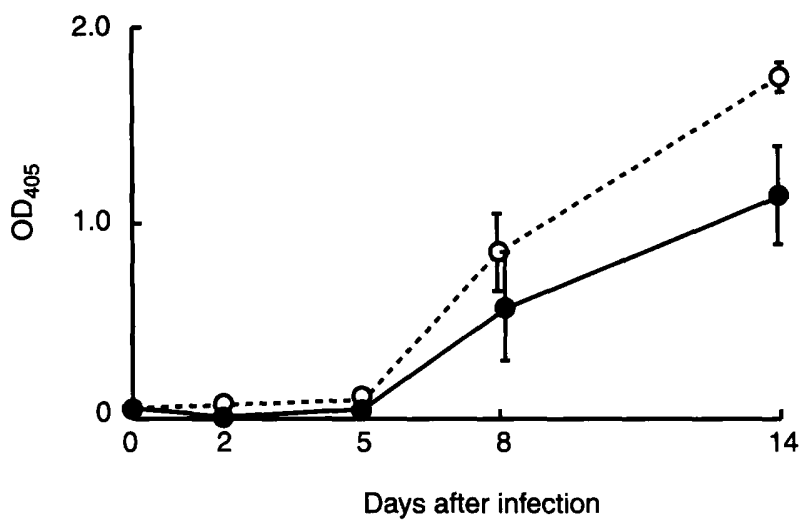

Fig. 3. Production of anti-pneumococcal antibody in sera of CBA/J mice infected with $S$. pneumoniae NNP-4 by an aerosol method with $(\bigcirc)$ or without $(O)$ ampicillin $200 \mathrm{mg} / \mathrm{kg}$ administered subcutaneously $1 \mathrm{~h}$ after the aerosol challenge. Antibody levels were examined by ELISA with microwells coated with heat-killed $S$. pneumoniae NNP-4. Data are expressed as mean and $\mathrm{SD}$ of three mice.

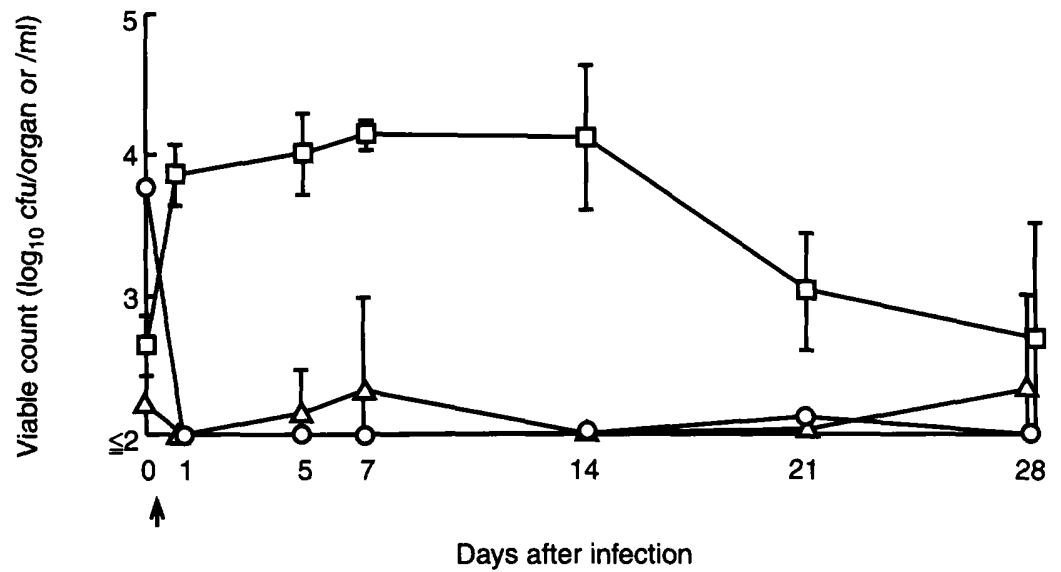

Fig. 2. Kinetics of bacterial counts in lungs $(O)$, trachea $(\triangle)$ and nasal washing $(\square)$ of mice treated with ampicillin $200 \mathrm{mg} / \mathrm{kg}(\uparrow) 1 \mathrm{~h}$ after the aerosol challenge with $S$. pneumoniae NNP-4. Data are expressed as mean and SD of five mice. 
Production of lower respiratory tract infection by airway obstruction

The effect of airway obstruction induced by an intratracheal injection with formalin was examined in mice with nasal colonisation by $S$. pneumoniae NNP-4 before and after antibody production. Formalin was injected on day 2 or 16 (before and after production of antibody) after bacterial challenge and ampicillin treatment. Bacterial counts in the lungs and nasal washings were done on day 4 after each injection of formalin. S. pneumoniae NNP-4 was recovered from the lungs of half the mice treated with formalin on day 16 after infection (Fig. 4). When formalin was injected on day 2 after infection, one of six mice died on day 3 ; all the surviving mice showed a positive bacterial recovery in their lungs. Bacteraemia was rare in surviving mice (data not shown). On the other hand, bacterial counts in the nasal cavity were slightly increased in both groups given formalin (Fig. 4). As lower respiratory tract infection was produced by the nasal organisms at an early stage, i.e., before the production of antibody, events at the early stages of infection were studied.

At the time formalin was given, anaesthesia, cervical incision, intubation and injection were performed. The effect of these procedures on the induction of lower respiratory tract infection by the pneumococci in the nasal cavity was examined. On day 1 after infection,

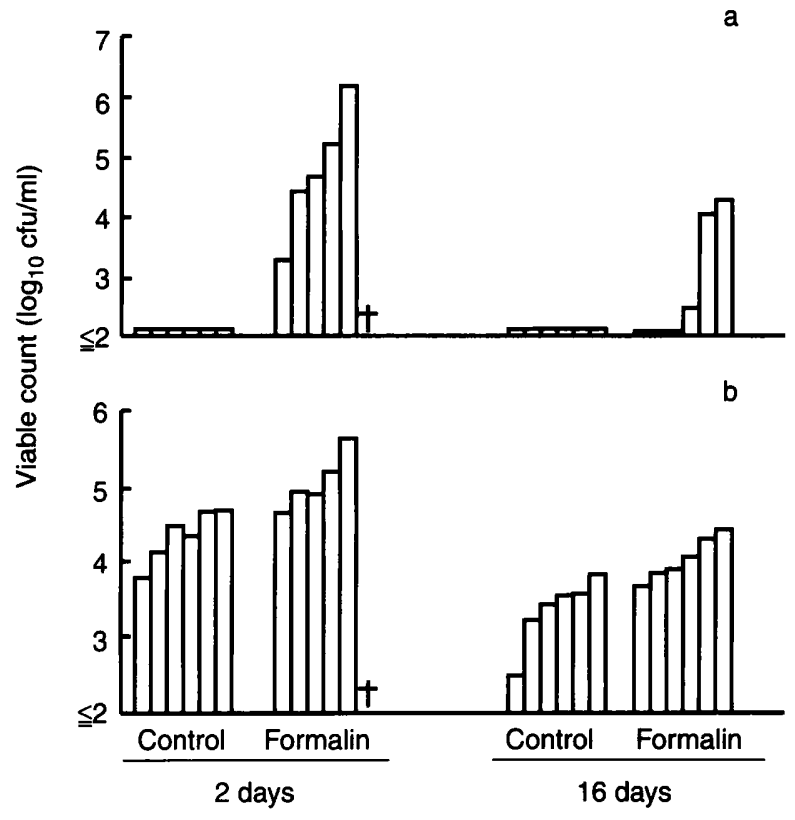

Fig. 4. Influence of time of administration of formalin on the induction of lower respiratory tract infection in a murine model of nasal colonisation by $S$. pneumoniae NNP-4. CBA/J mice were treated with ampicillin $200 \mathrm{mg} / \mathrm{kg} 1 \mathrm{~h}$ after the aerosol challenge with $S$. pneumoniae NNP-4. Intratracheal injection of $20 \mu \mathrm{l}$ of formalin $2 \%$ was done on days 2 or 16 after infection. The bacterial counts in (a) lungs and (b) nasal washings were examined on day 4 after each injection of formalin. Each bar represents the value for a mouse; $\dagger$, dead mouse. all mice were intubated trans-orally with a blunt needle after cervical incision. Some mice were given injections with $20 \mu \mathrm{l}$ of saline or formalin $2 \%$; other mice received neither. Bacterial counts in the lungs and nasal cavity were examined after 5 days. There were no bacteria in the lungs of mice that were intubated only (Fig. 5). Half the mice intubated and given saline showed positive bacterial recovery in the lungs. However, one of six mice given formalin died and all the remaining mice had $10^{5}-10^{6} \mathrm{cfu}$ of $S$. pneumoniae in their lungs. These results indicated that the damage to the respiratory mucosa by formalin is important in the invasion of the lungs by $S$. pneumoniae from the nose.

\section{Kinetics of bacterial counts in lungs after injection of formalin}

Formalin was injected into the trachea on the day after the mice were infected and the kinetics of bacterial counts in the lungs were examined; $6 \mathrm{~h}$ after formalin was given there were $10^{3}-10^{4} \mathrm{cfu}$ in the lungs (Fig. 6). These counts increased to around $10^{6} \mathrm{cfu}$ by the following day and remained at this level after $48 \mathrm{~h}$. To prove that the colonising organisms in the nasal cavity migrate to the lower respiratory tract not only after administration of formalin but also after airway obstruction, ampicillin was administered $1 \mathrm{~h}$ after formalin. Bacteria were killed within $6 \mathrm{~h}$ of administration of formalin (Fig. 6). However, in some mice given ampicillin after formalin, $S$. pneumoniae reappeared in the lungs on the following day and the bacterial counts increased thereafter, although levels were lower than in mice not given ampicillin after formalin. These results indicate that organisms in the nasal cavity migrate to the lower respiratory tract and can localise and proliferate in lungs when there is airway obstruction.

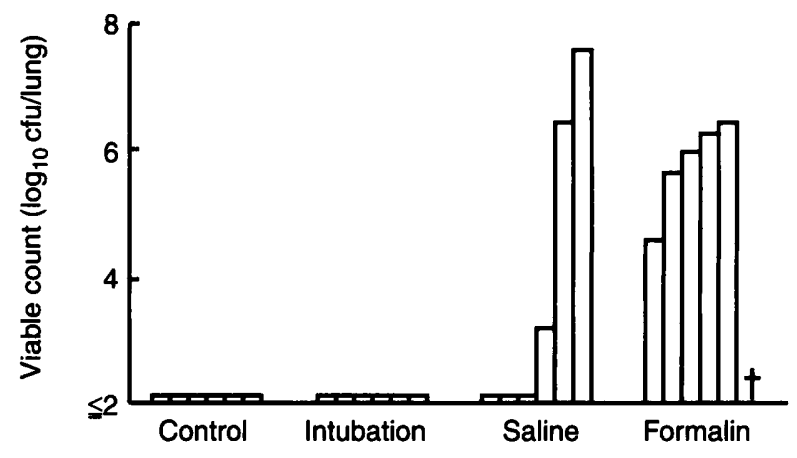

Fig. 5. Influence of intubation and saline injection on the induction of lower respiratory tract infection in a murine model of intranasal colonisation by $S$. pneumoniae NNP4. CBA/J mice were treated with ampicillin $200 \mathrm{mg} / \mathrm{kg}$ $1 \mathrm{~h}$ after the aerosol challenge with $S$. pneumoniae NNP4. Intubation and intratracheal injection of $20 \mu \mathrm{l}$ of saline or formalin $2 \%$ were done on day 1 after infection. The bacterial counts in lungs were examined on day 5 after the treatment. Each bar represents the value for a mouse; $\dagger$, dead mouse. 


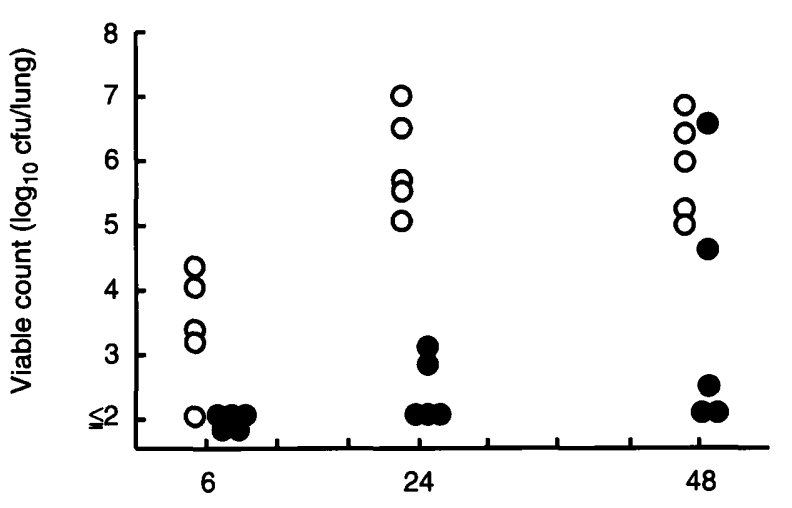

Time (h) after formalin treatment

Fig. 6. Kinetics of bacterial counts in lungs of mice after formalin treatment. Mice were infected with $S$. pneumoniae NNP-4 by an aerosol method. Ampicillin $200 \mathrm{mg} / \mathrm{kg}$ was administered subcutaneously $1 \mathrm{~h}$ after the aerosol challenge. Intratracheal injection of $20 \mu \mathrm{l}$ of formalin $2 \%$ was done on day 1 after infection. In some mice, ampicillin $100 \mathrm{mg} / \mathrm{kg}$ was again administered $1 \mathrm{~h}$ after the formalin. Bacterial counts in lungs were examined at indicated times after the administration of formalin. Each point represents the value for a mouse. $O$, mice given formalin; mice given formalin followed by ampicillin.

\section{Discussion}

Most infants are colonised with pneumococci on at least one occasion in the first 2 years of life [8]. Carriage rates are inversely related to age, but increase again in old people $[8,9]$. Recent studies have demonstrated that $S$. pneumoniae binds to glycoconjugate receptors; GalNAc $\beta 1-4 \mathrm{Gal}$, GalNAc $\beta 1-3 \mathrm{Gal}$, GlnNA$c \beta 1-3 \mathrm{Gal}$ on epithelial cells and endothelial cells [1619] and platelet-activating factor receptors on lung cells and endothelial cells [20]. Although the adhesins of $S$. pneumoniae have not been identified, some cellwall components and proteins are reported to participate in the adherence of $S$. pneumoniae to the glycoconjugate receptors $[21,22]$. However, the mechanisms by which $S$. pneumoniae in the respiratory tract moves into the lower respiratory tract and causes pneumonia have not been investigated to our knowledge.

When CBA/J mice were challenged with an aerosol containing $S$. pneumoniae NNP-4, the bacteria were eradicated from the lungs of some mice but remained at the initial level in others (data not shown). On the other hand, there were constant numbers of bacteria, unrelated to the bacterial counts in lungs, in the nasal cavity for $>2$ weeks. As the concentration in nasal secretions after parenteral administration of an antibiotic is considered to be lower than in lungs, we tried to eliminate the bacteria from lungs of mice with ampicillin after aerosol challenge with $S$. pneumoniae NNP-4. When $200 \mathrm{mg}$ of ampicillin $/ \mathrm{kg}$ was administered subcutaneously $1 \mathrm{~h}$ after the aerosol challenge, bacteria were eradicated from the lungs of the mice; however, ampicillin did not affect bacterial counts in the nasal cavity. Bacteria survived in the nasal cavity for $>2$ weeks. Thus, a model of persistent colonisation of the nasal cavity by $S$. pneumoniae was established.

It is postulated that nasopharyngeal carriage of pneumococci in man results in an immune response and that the immune status of the host is an important determinant of whether or not nasopharyngeal organisms spread to other areas $[4,6,7]$. Thus, this study investigated whether the organisms in the nasal cavity could induce an immune response. IgG antibody against the organisms was produced in sera around 1 week after infection. Therefore, nasal carriage of $S$. pneumoniae could cause systemic immunity. Neither IgG nor IgA antibodies against the organism were detected in bronchoalveolar lavage fluids, nor were any inflammatory responses in lungs, trachea or nasopharynx observed by histopathological examination (data not shown). Therefore, it is unclear in which area the immune response occurred.

The possibility that lower respiratory tract infections are produced by $S$. pneumoniae from the upper respiratory tract before the establishment of immunity was examined. Since the mucociliary transport system is considered to be one of the major non-specific mechanisms of clearance of organisms, formalin $2 \%$ was injected into the trachea in order to damage epithelial cells in the airway. S. pneumoniae appeared in the lungs of all mice given injections of formalin before the production of antibody, whereas only half the number of mice had $S$. pneumoniae in their lungs following formalin treatment after antibody had been produced. These results confirmed the previous beliefs that infections occur early in carriage $[4,6,7]$. Even at the early stage of nasal carriage, intubation alone did not induce infections, an indication that procedures such as anaesthesia, incision and intubation had no influence on the migration of pneumococci from the nasopharynx to the lungs. Although intratracheal injection of saline induced lower respiratory tract infections in half the number of mice, the effect of this was less than with formalin treatment, therefore the airway obstruction caused by formalin probably impaired the mucociliary transport system. The fact that injection of saline caused infections in some mice suggests that aspiration can also precipitate pneumococcal pneumonia when $S$. pneumoniae colonises the upper respiratory tract.

In the early stages of infection, organisms appeared in the lungs $6 \mathrm{~h}$ at the latest after the formalin was given; the bacterial counts in lungs increased thereafter. Small numbers of organisms were seen in lungs immediately after the formalin was given (data not shown), although the exact number of bacteria in lung homogenates was difficult to assess in the presence of formalin. Thus it is postulated that the organisms invaded the lungs at the time of administration of 
formalin and then proliferated. However, it was also shown that the colonising organisms in the nasal cavity invaded the lower respiratory tract continuously, since bacteria entered the lungs even after the organisms appeared to be eradicated by the administration of ampicillin $1 \mathrm{~h}$ after formalin treatment.

Therefore, it is postulated that pneumococci that colonise the nasopharynx migrate towards the lungs but are mostly eliminated by the mucociliary transport system. When this system is impaired, the host is unable to remove them and bacteria are allowed to localise and proliferate.

\section{References}

1. Berk SL, Verghese A. Emerging pathogens in nosocomial pneumonia. Eur J Clin Microbiol Infect Dis 1989; 8: 11-14.

2. Gillespie SH. Aspects of pneumococcal infection including bacterial virulence, host response and vaccination. $J$ Med Microbiol 1989; 28: 237-248.

3. Marrie TJ. Bacteraemia pneumococcal pneumonia: a continuously evolving disease. J Infect 1992; 24: 247-255.

4. Vathanophas K, Sangchai R, Raktham S et al. A communitybased study of acute respiratory tract infection in Thai children. Rev Infect Dis 1990; 12 Suppl 8: S957-S965.

5. Montgomery JM, Lehmann D, Smith $\mathrm{T}$ et al. Bacterial colonization of the upper respiratory tract and its association with acute lower respiratory tract infections in Highland children of Papua New Guinea. Rev Infect Dis 1990; 12 Suppl 8: S1006-S1016.

6. Paton JC, Andrew PW, Boulnois GJ, Mitchell TJ. Molecular analysis of the pathogenicity of Streptococcus pneumoniae: the role of pneumococcal proteins. Annu Rev Microbiol 1993; 47: $89-115$

7. Smith T, Lehmann D, Montgomery J, Gratten M, Riley ID, Alpers MP. Acquisition and invasiveness of different serotypes of Streptococcus pneumoniae in young children. Epidemiol Infect 1993; 111: 27-39.

8. Musher DM. Infections caused by Streptococcus pneumoniae: clinical spectrum, pathogenesis, immunity, and treatment. Clin Infect Dis 1992; 14: 801-809.

9. Boulnois GJ. Pneumococcal proteins and the pathogenesis of disease caused by Streptococcus pneumoniae. J Gen Microbiol 1992; 138: 249-259.

10. Busse WW. Pathogenesis and sequelae of respiratory infections. Rev Infect Dis 1991; 13 Suppl 6: S477-S485.

11. Johnston RB. Pathogenesis of pneumococcal pneumonia. Rev Infect Dis 1991; 13 Suppl 6: S509-S517.

12. Bruyn GAW, Zegers BJM, van Furth R. Mechanisms of host defense against infection with Streptococcus pneumoniae. Clin Infect Dis 1992; 14: 251-262.

13. Lindberg K, Freijd A, Rynnel-Dagoo B, Hammarstrom L. Anti-pneumococcal antibody activity in nasopharyngeal secretions in healthy adults and children. Acta Otolaryngol (Stockh) 1993; 113: 673-678.

14. Murphy TF, Sethi S. Bacterial infection in chronic obstructive pulmonary disease. Am Rev Respir Dis 1992; 146: 1067-1083.

15. Iizawa $Y$, Nishi $T$, Kondo M, Imada A. Experimental chronic pulmonary infection in mice caused by Klebsiella pneumoniae. Microbiol Immunol 1988; 32: 895-906.

16. Andersson B, Dahmén J, Freijd $\mathrm{T}$ et al. Identification of an active disaccharide unit of a glycoconjugate receptor for pneumococci attaching to human pharyngeal epithelial cells. $J$ Exp Med 1983; 158: 559-570.

17. Cundell DR, Tuomanen EI. Receptor specificity of adherence of Streptococcus pneumoniae to human type-II pneumocytes and vascular endothelial cells in vitro. Microb Pathog 1994; 17: 361-374.

18. Krivan HC, Roberts DD, Ginsburg V. Many pulmonary pathogenic bacteria bind specifically to the carbohydrate sequence GalNAc $\beta 1-4 \mathrm{Gal}$ found in some glycolipids. Proc Natl Acad Sci USA 1988; 85: 6157-6161.

19. Sundberg-Kövamees M, Holme T, Sjögren AM. Specific binding of Streptococcus pneumoniae to two receptor saccharide structures. Microb Pathog 1994; 17: 63-68.

20. Cundell DR, Weiser JN, Shen J, Young A, Tuomanen EI Relationship between colonial morphology and adherence of Streptococcus pneumoniae. Infect Immun 1995; 63: 757-761.

21. Andersson B, Beachey EH, Tomasz A, Tuomanen E, SvanborgEdén C. A sandwich adhesin on Streptococcus pneumoniae attaching to human oropharyngeal epithelial cells in vitro. Microb Pathog 1988; 4: 267-278.

22. Geelen S, Bhattacharyya C, Tuomanen E. The cell wall mediates pneumococcal attachment to and cytopathology in human endothelial cells. Infect Immun 1993; 61: 1538-1543. 